\title{
VEHICLE RESTRAINT SYSTEM OPTIMIZATION FOR FRONTAL IMPACT
}

\author{
Anderson de Lima ${ }^{1}$, Mateus A. Santa Rosa ${ }^{1}$, Brian Callaghan ${ }^{1}$ and Carlos A. Prado Guido ${ }^{1}$ \\ ${ }^{1}$ General Motors do Brasil \\ E-mails: andersonkaipers.lima@gm.com, brian.callaghan@gm.com, carlos.guido@gm.com, \\ mateus.rosa@gm.com
}

\begin{abstract}
The Brazilian Automotive regulations that are aimed towards the safety of drivers, passengers and pedestrians have gone through recent changes to prevent and/or minimize injury and trauma from different types of accidents.

Until now, National Traffic Council (CONTRAN) Resolution $n^{\circ} 14 / 98$ required vehicles to only have safety belts for an occupant restraint system, and frontal airbags were not required. Since the recent CONTRAN n ${ }^{\circ} 311 / 09$ Resolution requires mandatory frontal airbags, the occupant restraint system must be tuned due to the interaction with different components that may make up the system, like safety belts with pretensioners and seatbelt load limiting devices.
\end{abstract}

The present study was developed to optimize the restraint system of a current vehicle in production, while focusing on minimizing the vehicle complexity. The optimization tool helped to develop a robust restraint system for the frontal passenger during a frontal impact [1].

The numerical computational model created was initially correlated with an experimental test, and then 72 simulations were performed to build the optimization matrix. The optimized parameters provided by the Design of Experiments (DOE) were simulated in the numerical computational model and also applied in an experimental test. The results presented excellent correlation and the goals of the optimization were achieved showing that this tool can help in future developments. This paper will review the methods used to study variables in restraint system with respect to their effect on occupant performance, as well as explain the final results from this optimization study.

\section{INTRODUCTION}

During a frontal collision, the restraint system may help mitigate injuries of the occupants. The term restraint system means the set of devices that assist in occupant protection during a collision event. Examples are seats, seatbelts, airbags, instrument panels, and child restraint systems. Figure 1 shows such examples. 


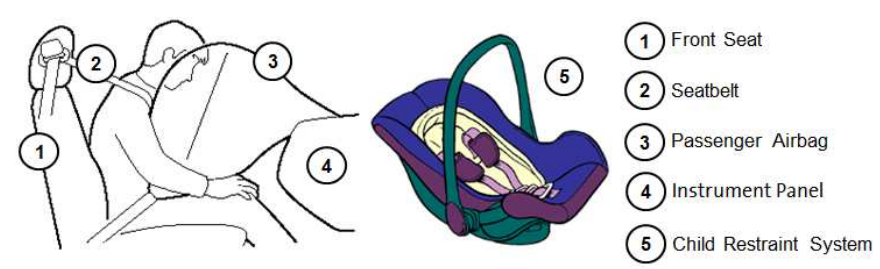

Figure 1. Examples of vehicle restraint systems

Beginning in 2014, CONTRAN regulation established from Resolution No. 311/09, that all models manufactured must have mandatory frontal airbags and also must meet front and rear crash requirements in accordance with Resolution No. 221/07. The purpose of these regulations was to bring improvements of occupant performance and lead to safer products for the automotive customers. Figure 2 describes the roll-out phase for frontal airbags implementation as well as the crashworthiness requirements that must be met for Brazil.

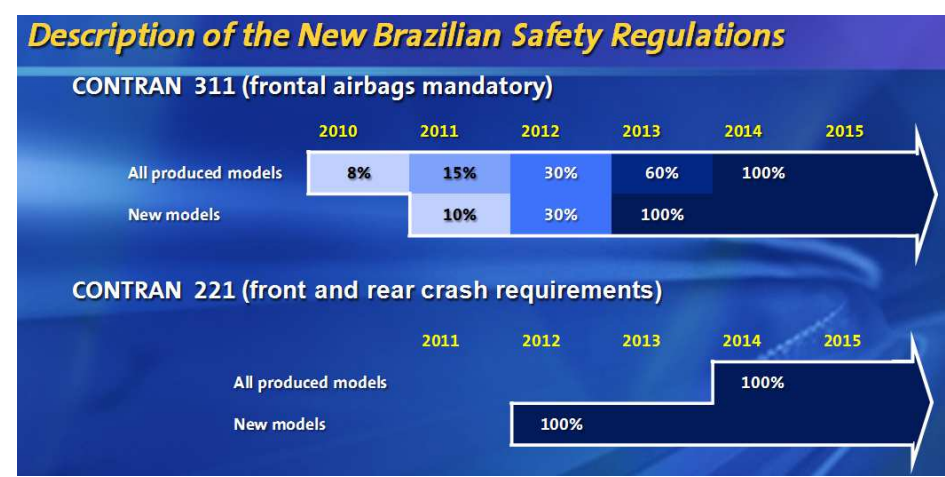

Figure 2. CONTRAN 311 and 211 roll-out phases

The primary goal of this project was to optimize the restraint system of a current vehicle in production using Design For Six Sigma (DFSS) optimization tools [2]. The optimization tools helped to develop a robust restraint system to CONTRAN Resolution No. 221/07 (which will be a legal requirement for all produced models in 2014) with robust safety margin.

This paper will only focus on the frontal passenger restraint system optimization to simplify the amount of simulations that would be necessary if driver and passenger restraint optimization were simultaneously combined. The optimization results will be based on a frontal 40\% Overlap Deformable Barrier (ODB) impact at 56kph according to the ABNT NBR 15300 option 3 standard and test procedure based on Economic Commission Europe (ECE) R94 standard. The test shall be carried out with two 50th percentile male Hybrid III dummies at front seats, belted in a Left Hand Drive (LHD) vehicle. Figure 3 illustrates part of the test setup.

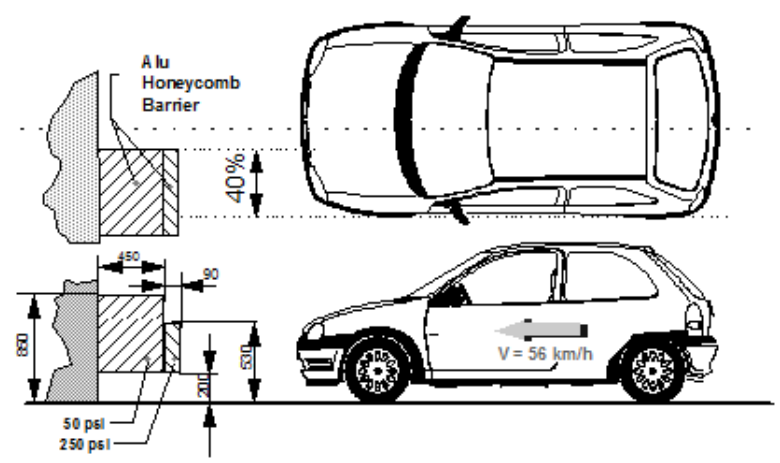

Figure 3. ECE R94 barrier test setup 
The project was carried out using a DFSS approach through the publicly popular IDOV (Identify - Design - Optimize - Validate) methodology. DFSS is a methodology for driving process capable designs that satisfy the customer by identifying and optimizing critical design parameters. It can be effectively applied at all levels of engineering development. The figure 4 outlines the DFSS step.

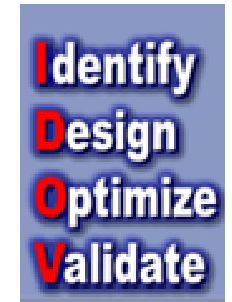

Figure 4. DFSS four steps

\section{METHODOLOGY}

\section{IDOV - Identify Phase}

This project phase will describe the opportunity to have a more efficient approach to better tune a passenger restraint system of a current vehicle in production. The potential benefit for the customer is to improve the occupant protection by reducing IARVs (Injury Assessment Reference Values) during a frontal impact.

In February of 2007, a survey was conducted with a group of 510 Brazilians drivers of São Paulo, Rio de Janeiro, Porto Alegre, Belo Horizonte and Salvador cities. One of the survey questions was "What is a safe car for you? Which equipment must be present?" Most drivers have stated that a safe car must contain at least three safety systems: safety belts $(66 \%)$, air bags (57\%) and Anti-lock Braking System (38\%). More detailed information about customer surveys, studies and campaigns will be explored on the next DFSS phase (IDOV - Design Phase).

The opportunity was to modify the current PAB (Passenger AirBag). The benefit is minimizing the vehicle complexity with this modified PAB.

In addition to taking advantage of this modification, the Vehicle Safety Team decided to apply the DFSS concepts to pursue opportunities to improve performance regarding the occupant protection, mainly for chest performance. Considering this modification of the PAB, the occupant restraint system must be tuned due to the interaction with different components that make up the restraint system, like safety belts with pretensioners and seatbelt load limiting devices.

Several variables were considered on this project and its benefits will be explored in details during the optimization phase. The chosen variables were as follow: seat belt elongation, pretensioner, load limit, seat belt height adjustment, seat back angle, tether length and location, airbag deploy time, airbag vent hole diameter, and dummy H-point. The H-point (or hip-point) is the theoretical, relative location of an occupant's hip, specifically the pivot point between the torso and upper leg portions of the body, relative to the floor of the vehicle. There are some components, like the passenger seat and instrument panel, which are carry-over from the current vehicle and will not be modified for this project. Figure 5 shows the scope of the project. 

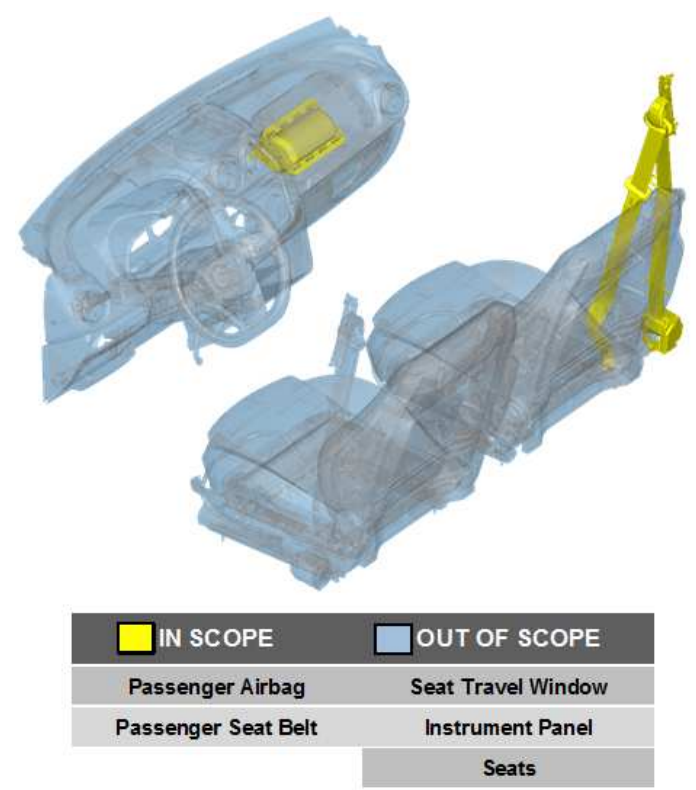

Figure 5. Project scope

\section{IDOV - Design Phase}

For this phase, it's necessary to define some inputs, like the customers for this project, the requirements, and the Voice of Customer (VOC). These inputs are divided into internal and external. No internal customer and VOC were identified for this project.

\section{External Costumers}

a. Vehicle Owners / Users

b. Brazilian Regulatory Agencies / Research Centers

\section{$\underline{\text { Requirement }}$}

CONTRAN Resolution No 221/2007: A legal requirement that establishes the vehicles with the test dummies must comply with the occupant protection requirements listed on table 1, according CONTRAN 221/07 (ABNT NBR 15300-3 - Road vehicles - Occupant protection Frontal crash test Option 3: frontal crash test procedure with $40 \%$ overlap). It was enforced in 5 years for new projects (30/Jan/2012), and in 7 years for all vehicles (30/Jan/2014).

Table 1. CONTRAN 221/07 Performance Requirements

\begin{tabular}{|c|c|c|c|}
\hline Dummy Region & Injury Criteria & Units & Values \\
\hline \multirow{2}{*}{ Head } & HIC (36ms) & {$[-]$} & 1000 \\
\hline & Resultant Acceleration & [g] & 80 \\
\hline \multirow{7}{*}{ Neck } & \multirow{3}{*}{ Axial Tension $(+\mathrm{Fz})$ Duration } & \multirow{6}{*}[\mathrm{N}]{} & $3300(0 \mathrm{~ms})$ \\
\hline & & & $2900(35 \mathrm{~ms})$ \\
\hline & & & $1100(\geq 60 \mathrm{~ms})$ \\
\hline & \multirow{3}{*}{ Shear Load $(+\mathrm{Fx})$ Duration } & & $3100(0 \mathrm{~ms})$ \\
\hline & & & $1500(25-35 \mathrm{~ms})$ \\
\hline & & & $1100(\geq 45 \mathrm{~ms})$ \\
\hline & Rearward Moment & {$[\mathrm{Nm}]$} & 57 \\
\hline \multirow{2}{*}{ Thorax } & Compression (belted) & {$[\mathrm{mm}]$} & 50 \\
\hline & Viscous Criterion & {$[\mathrm{m} / \mathrm{s}]$} & 1.0 \\
\hline
\end{tabular}




\begin{tabular}{|c|c|c|c|}
\hline \multirow{2}{*}{ Femur } & Compressive Load - Duration & \multirow{2}{*}[\mathrm{N}]{} & $9070(0 \mathrm{~ms})$ \\
\cline { 3 - 4 } & & $7580(10 \mathrm{~ms})$ \\
\hline \multirow{2}{*}{ Tibia } & Axial Compressive Load & {$[\mathrm{N}]$} & 8000 \\
\cline { 2 - 4 } & Index $=$ M/Mc $+|\mathrm{P}| / \mathrm{Pc}$ & {$[-]$} & 1.3 \\
\hline Knee & Sliding (Tibia-Femur) & {$[\mathrm{mm}]$} & 15 \\
\hline
\end{tabular}

\section{$\underline{\text { External Voice Of Customer (VOC) }}$}

The project team assumed that the VOC (regarding the occupant protection during frontal collision events), have two main sources:

1. Brazilian Regulatory Agencies and Research Centers data (studies, surveys, guidelines etc)

2. Statements from vehicle owners and users (internet forums and interviews)

\section{National Traffic Department (DENATRAN) Voice}

DENATRAN hosts campaigns to encourage the use of seat belts that show the benefits of various restraint systems and how to use the restraint system correctly to help mitigate serious injuries during frontal collision events. Figure 6 illustrates the DENATRAN hotsite.

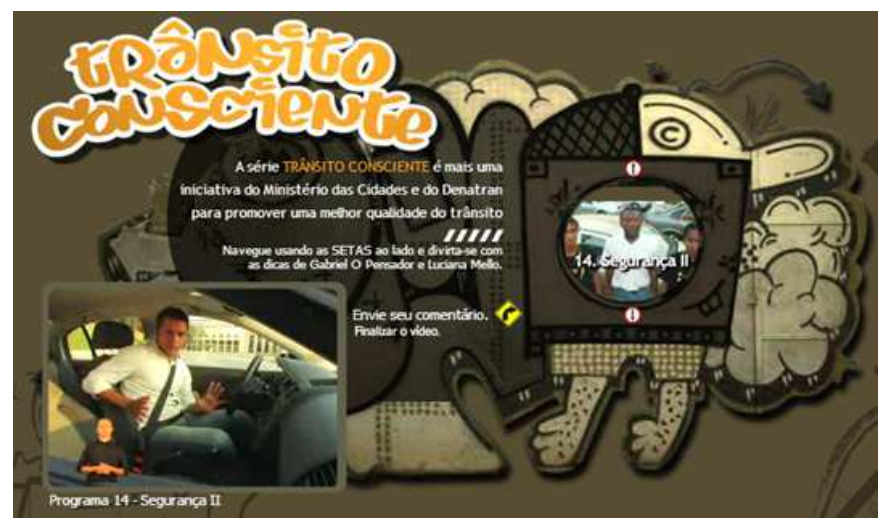

Figure 6. DENATRAN campaign

\section{Research Center (CESVI BRASIL) Voice}

CESVI BRASIL performed research to evaluate the impact of adopting frontal airbags in the Brazilian vehicles, focusing on the potential reduction of fatalities and injuries. The conclusion was that the frontal airbags could potentially reduce 490 deaths per year $(1.4 \%)$ or prevent injuries in more than 10.000 people, which could potentially contribute to a savings of 175 million dollars for the public health system. Figure 7 shows one of the polls made by CESVI, regarding the use of safety belts.

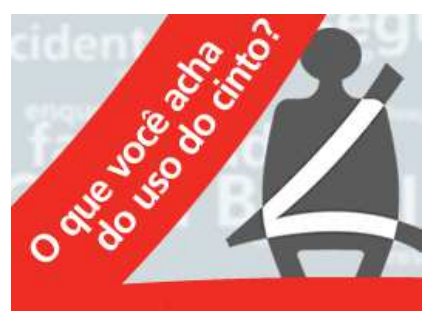

Figure 7. CESVI BRASIL safety belt poll 


\section{Customer's Voice (Internet discussion forums)}

Some examples from internet forums and interviews are shown here regarding the relative importance of customer voice when it comes to vehicle safety:

1. Htforum.com: “...I'm looking for a used car. I am crazy about safety and would not be able to buy a car without an airbag. Since 2001 my cars have this equipment and don't see me not using it..."

2. Tdmoose.com: "...I'm convinced that the airbag in my car saved my life, allowing me to sit here and write this..."

3. Team-bhp.com: "...my Cedia had taken all the impact of the collision with the Tata Sumo and I was not hurt due to the seat belt keeping me in place and the airbags deploying preventing any head injuries..."

4. Team-bhp.com: "...Fortunately we were both safe. Guess who was the hero of the day? "SEAT BELTS". If I wasn't wearing them I would have surely been thrown out of the windshield. We both were wearing seat belts..."

5. Mylot.com: “...I know I would not buy a vehicle without seatbelts or air bags, not only because it would not pass inspection - but I want safety - Sure things were different back 20-30 years ago - but as technology changes - safety gets more detailed and better - So I would not purchase a vehicle without either..."

The VOC analyses show the importance of having vehicles with seat belts and airbags. Consequently, a well-balanced restraint system is desired to meet the requirements and guarantee customers satisfaction.

Continuing with the Design Phase, ideas were generated to select the best option for reducing vehicle complexity, based on some creative techniques.

For this project, a benchmarking technique was used. The second step was to select some concepts based on the previous work and benchmarking analyses done. Concepts selection will be based on a function analysis, called function tree, and a decision-matrix method known as a Pugh Matrix that is a quantitative technique invented by Dr. Stuart Pugh. This refers to a matrix that helps determine which items or potential solutions are more important or "better" than others. The third step was choosing the best concept. This selection is made based on consolidated scores. Figure 8 illustrates in details how to develop a concept.

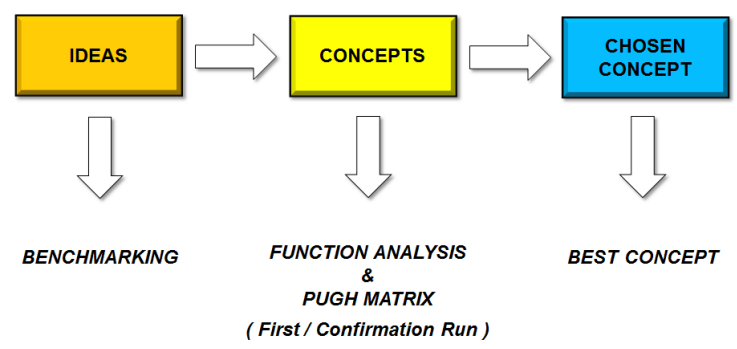

Figure 8. Develop concept flowchart

\section{$\underline{\text { Benchmark }}$}

The benchmarking study for this project considered some concepts of passenger seat belt and PAB. Figure 9 illustrates a passenger seat belt that uses a mechanical load limiter concept without pretensioner. 


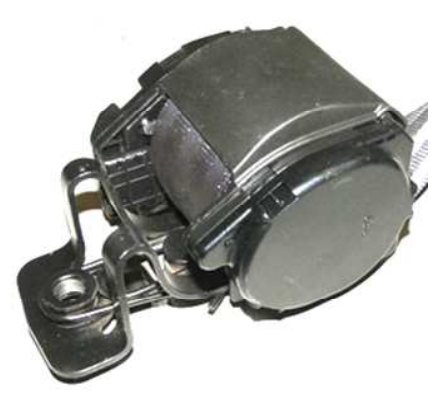

Figure 9. Benchmarking \#1

Figure 10 illustrates another passenger seat belt concept, which uses a pretensioner on the retractor with torsion bar load limiter type.

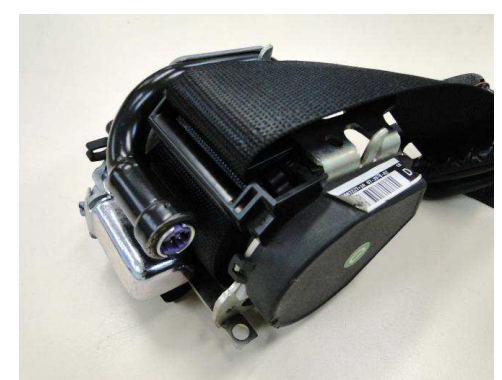

Figure 10. Benchmarking \#2

Figure 11 shows a PAB with 2 longitudinal tethers and 2 vent holes (30mm of diameter). This $\mathrm{PAB}$ has an estimated volume of 80 liters.

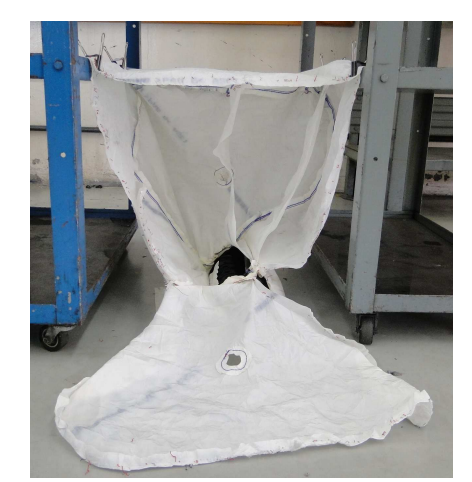

Figure 11. Benchmarking \#3

\section{Function Analysis \& Pugh Matrix}

A function analysis (or function tree) is a hierarchical representation of the functions of a system and summarizes how a design accomplishes the values and quality that is required in a product. For this project, it was used to:

1. Conduct structure analysis ("how do I satisfy this function?")

2. Conduct function analysis ("why do you need this function?")

3. Drive technical requirements ("how do you measure the performance of the function?") 
Figure 12 explains in details the function analysis for this project based on the scope.

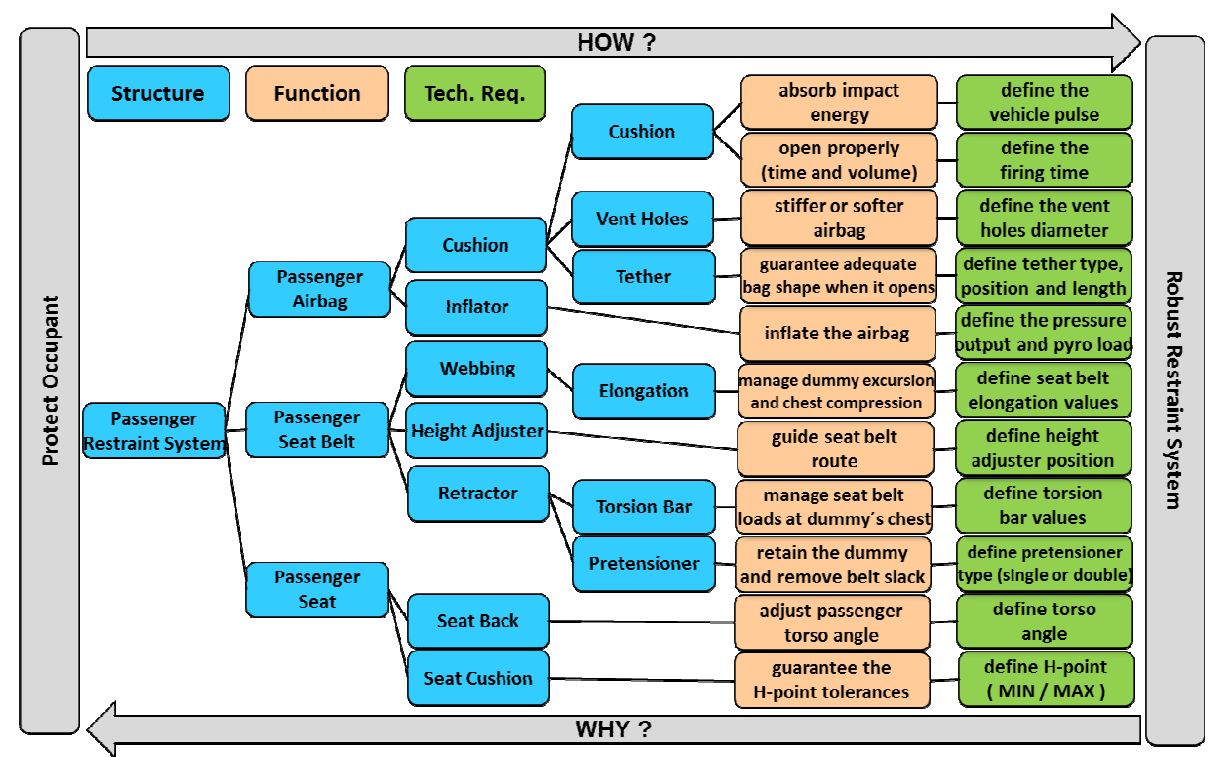

Figure 12. Function Tree

The Pugh matrix allowed the engineers to compare different concepts for the passenger seat belt and PAB. For the seat belt, 4 concepts were defined according to their strengths and weaknesses against a reference concept called the DATUM (base concept). The DATUM is the best current concept at each iteration of the matrix. Figure 13 shows the seat belt concepts chosen for this project.

\begin{tabular}{|c|c|c|c|}
\hline $\mathbf{0}$ (DATUM) & $\mathbf{1}$ & $\mathbf{2}$ & $\mathbf{3}$ \\
\hline $\begin{array}{c}\text { Standard Retractor } \\
\text { (wio load limiter and } \\
\text { pretensioner) }\end{array}$ & $\begin{array}{c}\text { Retractor with } \\
\text { Load Limiter }\end{array}$ & $\begin{array}{c}\text { Retractor with } \\
\text { Load Limiter }+ \\
\text { Pretensioner }\end{array}$ & $\begin{array}{c}\text { Retractor with } \\
\text { Mechanical } \\
\text { Load Limiter }\end{array}$ \\
\hline & &
\end{tabular}

Figure 13. Passenger seat belt concept selection

For the PAB, 2 concepts were defined. Figure 14 illustrates the airbag concepts for this project.

\begin{tabular}{|c|c|}
\hline 0 (DATUM) & 1 \\
\hline$P A B$ without tether & $P A B$ with lateral tether \\
\hline
\end{tabular}

Figure 14. PAB concept selection 
Since the concepts were defined, it's necessary to select the criteria in order to populate the Pugh matrix and choose the best concept. For this project, the criteria were piece cost, investment, package, chest compression performance, mass, timing development, and dependence on other systems.

Figure 15 shows the first run for the passenger seat belt. The DATUM turned out to be the best in all categories except chest compression performance. The DATUM concept is a standard retractor, without load limiter and pretensioner.

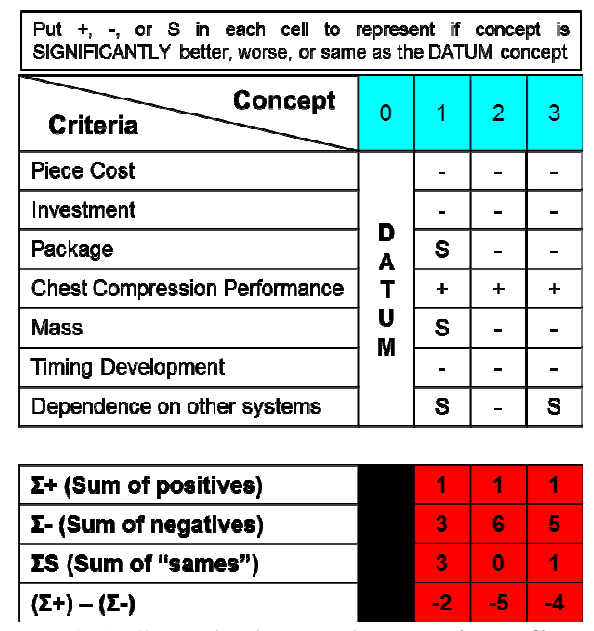

Figure 15. Seat belt Pugh matrix - first run

Due to DATUM being the best, a new Pugh matrix was run with another chosen DATUM. In this case, the concept 1 was selected as DATUM. Based on the score of the confirmation run, the concept 1 proved to be the test. Figure 16 shows the score.

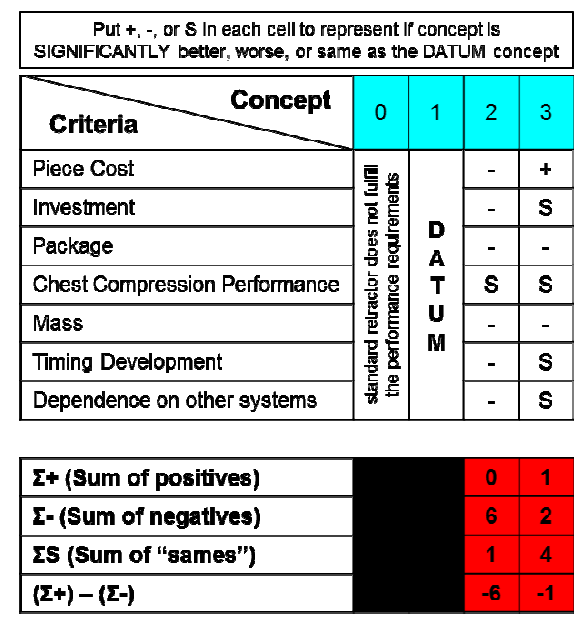

Figure 16. Seat belt Pugh matrix - confirmation run

Figure 17 shows the first run for the PAB. The DATUM turned out to be the best and fulfill the chest compression performance requirement. Based on this, no confirmation run is necessary for the PAB Pugh matrix. The DATUM concept is a PAB without a lateral tether. 

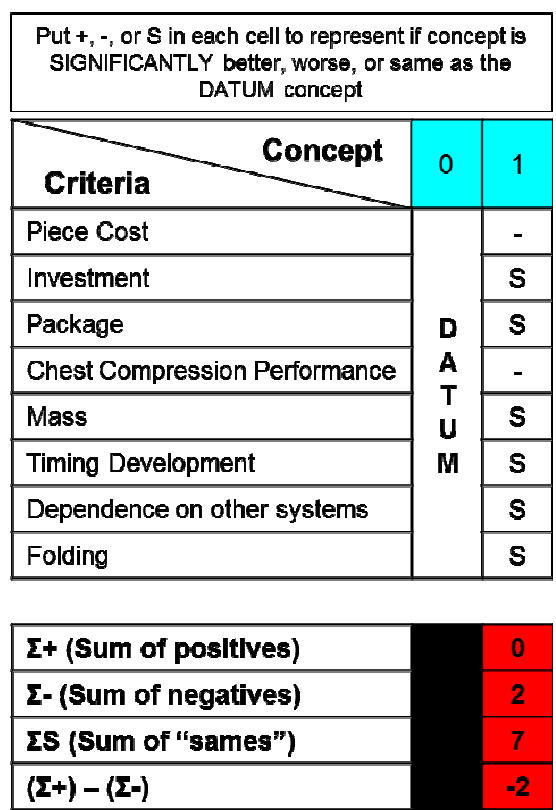

Figure 17. PAB Pugh matrix - first run

\section{$\underline{\text { Best Concept }}$}

Based on the passenger seat belt Pugh matrix confirmation run, the concept 1 (retractor with load limiter) might provide the best solution for the project. The recommendation was to verify during next DFSS phase, called optimization, the gains on chest compression with concept 1 . For the PAB, the concept 0 (PAB without tether) was recommend to be verified during the optimization phase, as the best concept for chest compression.

\section{IDQ V - Optimize Phase}

The goal of this phase is to optimize the product; setting the design parameters to ensure consistent performance under different operating conditions. However to conduct this optimization, it is necessary to understand better the transfer function approach. The transfer function for this project is a measure of the signal output versus the signal input of a vehicle restraint system during a frontal crash test. Mathematical dynamic models (MADYMO) [3] was used to assess restraint system performance during the optimization phase based on a single input vehicle configuration. Figure 18 illustrates this specific transfer function.

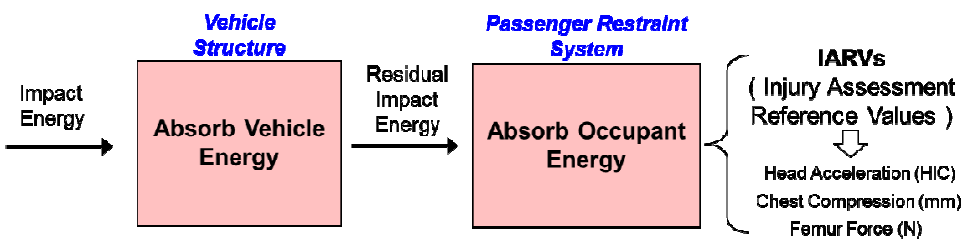

Figure 18. Crash test transfer function approach

\section{$\underline{\text { Optimization Steps }}$}

According to the DFSS approach, the optimization phase should consider some important steps in order to guarantee a robust engineering assessment. The steps are the following:

1. Identify scope 
2. Ideal function

3. Signal and noise factor strategy

4. Control factor strategy

5. Conduct experiment

6. Analyze data

7. Predict and confirm

8. Document

All these 8 steps were explored in details during this phase. The first 4 steps are the most important ones and shall be analyzed very well before starting data collection.

\section{$\underline{\text { Identify Scope }}$}

The project scope is to develop a passenger restraint system with the lowest chest compression value, that is robust to parameter variation and meets all CONTRAN required injury values. A system diagram (showed in Figure 19) is useful for describing the scope.

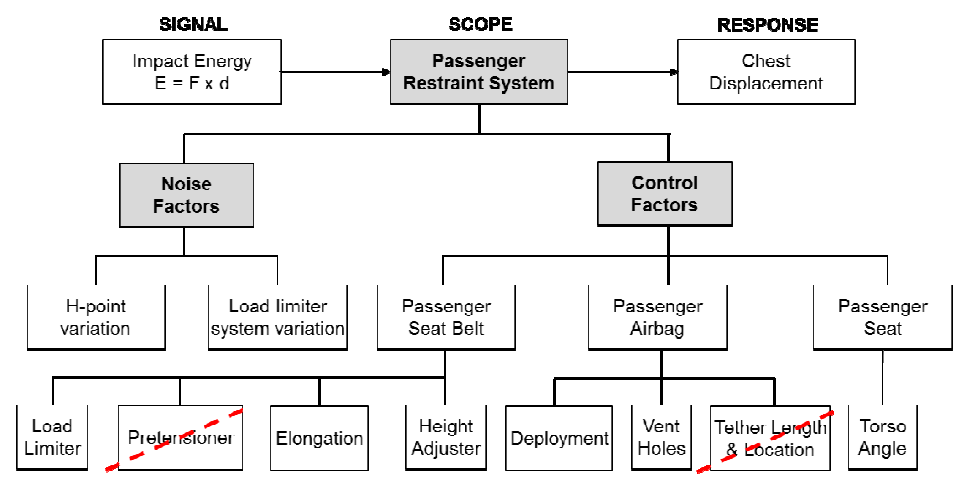

Figure 19. System diagram

The two dashed control factors were not be considered during optimization phase, based on Pugh matrix analyses, which selected the best airbag and seat belt concepts.

\section{Ideal Function}

The passenger restraint system (including safety belt, frontal airbag, seat, and instrument panel) should incrementally absorb the appropriate level of energy from the occupant throughout the restraint ride down period. The restraint loads must be balanced to provide uniform loading of the occupant. This perfect or ideal relationship is represented by the "ideal function". Figure 20 explores the energy transfer concept.

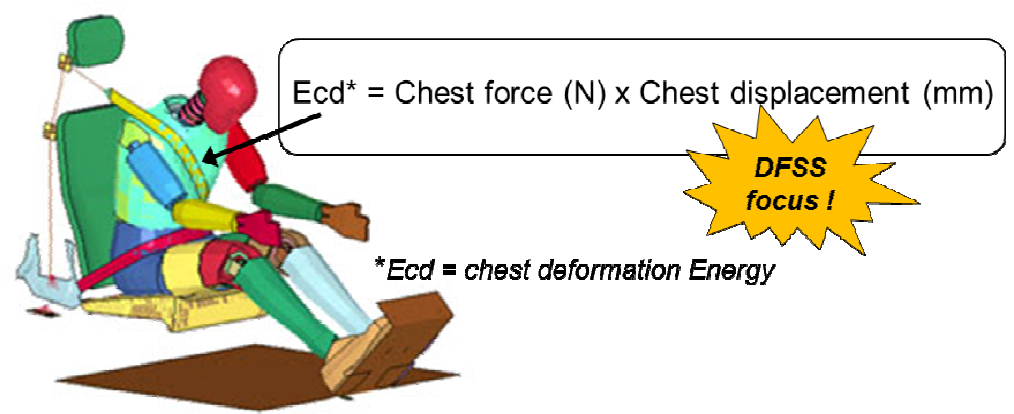

Figure 20. Energy transfer concept 


\section{Signal and noise factor strategy}

Signals and noise factors affect the energy transformation and resulting output. Therefore, one must subject a design to noise factors to determine its robustness and a signal that is intended to change the system response.

\section{Signal levels}

During the crash test phase of a current vehicle in production, several pulses were collected (blue, black and red curves shown on figure 21). The signal strategy for this project will be based on the worst case for frontal ODB crash test pulse. From this, a signal level strategy will be considered at one level.

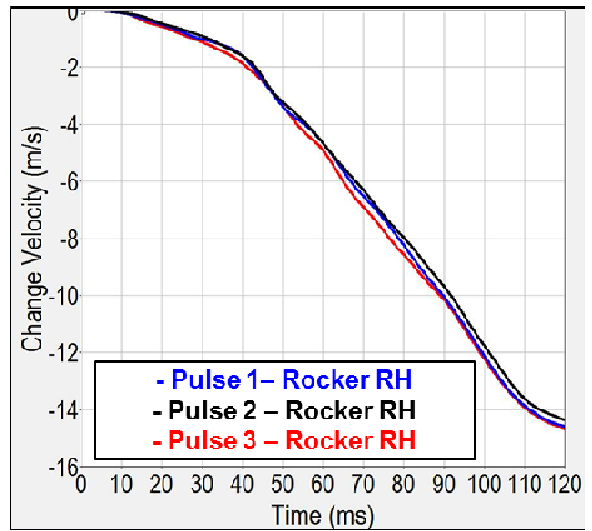

Figure 21. Frontal ODB crash test pulses

\section{Noise Factors}

Two noise factors were chosen considering the influence in the output response: load limiter system and $\mathrm{H}$-point ( $\mathrm{X} / \mathrm{Z}$ directions) variations. These chosen noise factors can be tested virtually by computer-aided engineering (CAE) analyses. The load limiter presents some variation during its activation. For this project, the variation adopted was $\pm 0.5 \mathrm{kN}$. From this, the virtual analyses was conducted varying passenger seat belt loads considering this range to understand which can affect chest compression results due to this variation. Figure 22 shows the three different load limiter values adopted for this project and its variations (upper, nominal and lower values).

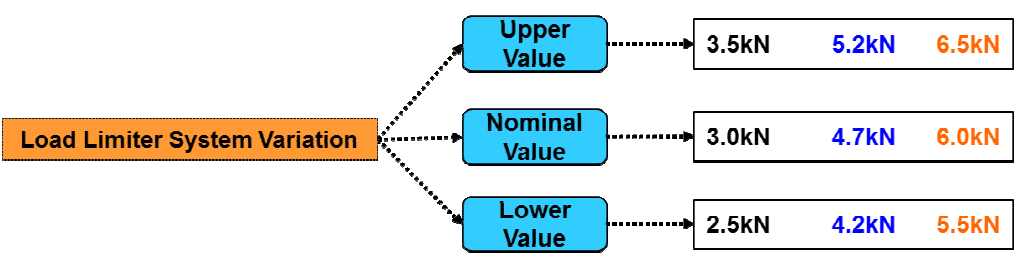

Figure 22. Load limiter variations

According to ABNT NBR 15300 option 1 standard, the H-point tolerance is $13 \mathrm{~mm}$. Therefore, the virtual analyses were conducted varying passenger test $\mathrm{H}$-point $(\mathrm{X}$ and $\mathrm{Z}$ directions) considering this range to understand which affected the chest compression results due to this variation. Figure 23 shows the nominal H-point value designed for this project and its variations (upper and lower values). 


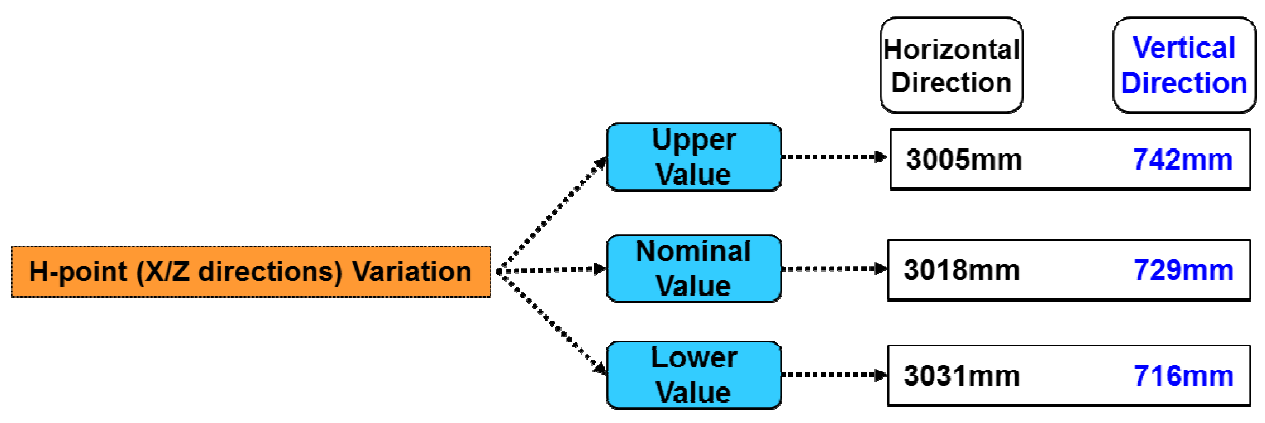

Figure 23. H-point variations

\section{Control factor strategy}

Control factors are design parameters that are expected to influence the relationship between the signal and response. For this project seven control factors were chosen to be evaluated during the optimization phase.

1. Load limiter: an enabler to balance performance parameters. The load limiter with torsion bar allows the belt to "pay out" or release in a controlled manner, especially in a higher energy collision. The three levels specified for this control factor are: $3.0 \mathrm{kN}$, $4.7 \mathrm{kN}$ and $6.0 \mathrm{kN}$.

2. Pretensioner: an enabler to balance performance parameters. The pretensioner can help reduces the forward motion of the occupant by tightening the belt webbing at the onset of a crash. Two levels were specified for this control factor: with and without pretensioner. The pretensioner effects will be verified as a learning, since Pugh Matrix did not recommend as the best concept.

3. Seat belt elongation: an enabler to balance performance parameters. The three levels specified for this control factor are $8 \%, 11 \%$ and $13 \%$.

4. Seat belt height adjuster: an enabler to balance performance parameters and assist in the performance of the passenger seat belt system by better matching the belt geometry to occupants of varying sizes. The three levels specified for the seat belt height adjuster for this project are: lower, medium and upper.

5. Airbag vent hole diameter: an enabler to balance performance parameters by controlling the discharge the gas from the inflator to the outside of the passenger airbag. The variation of the vent holes allows adjustment of the level of energy dissipated by the airbag. The three levels specified for this control factor are $30 \mathrm{~mm}$, $35 \mathrm{~mm}$ and $40 \mathrm{~mm}$.

6. Airbag deploy time: an enabler to balance performance parameters by controlling the time that the Sensing Diagnostic Module (SDM) will deploy the passenger airbag based on the crash severity. The three levels specified for this control factor are: $28 \mathrm{~ms}$, $32 \mathrm{~ms}$ and $36 \mathrm{~ms}$.

7. Seat back angle: an enabler to balance performance parameters by adjusting the angle. The angle must follow ABNT NBR 15300 option 1 standard. The three levels specified for this control factor are $21 \mathrm{deg}$, $23 \mathrm{deg}$ and $25 \mathrm{deg}$.

\section{Parameter Diagram}

A Parameter Diagram (P-Diagram) shows the relationship of the signals, noise factors, control factors, responses and symptoms. Constructing the P-Diagram, helps to identify the signal, noise factor and control factor strategy. Figure 24 illustrates the P-Diagram for this project. 


\section{Control Factors}

Passenger Airbag (deploy time, vent holes and tether length \& location) Passenger Seat Belt (load limiter, pretensioner, elongation and height adjuster) Passenger Seat (torso angle)

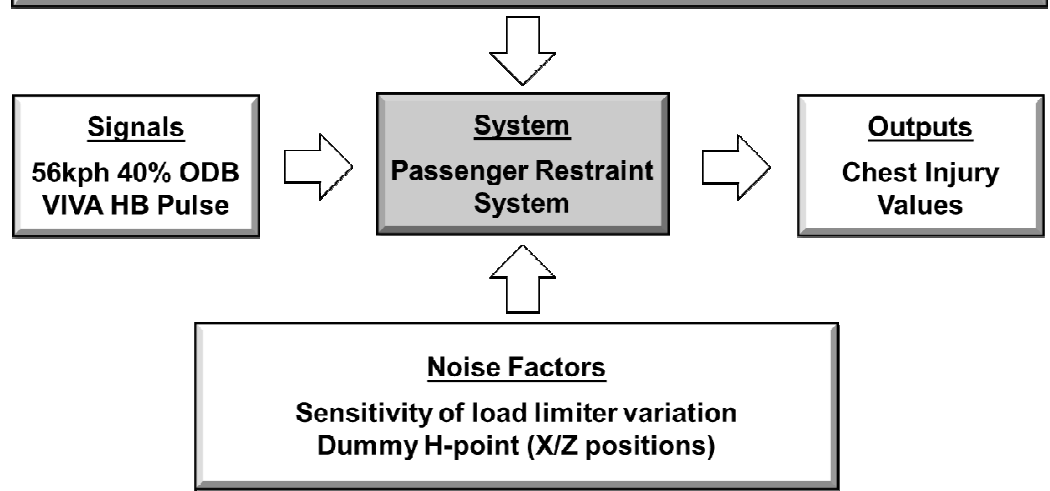

Figure 24. P-Diagram

\section{Conduct Experiment}

To conduct the experiment, an orthogonal array experimental design proposed by Dr. Genichi Taguchi of Japan was used. The experimental design proposed by Taguchi involved using orthogonal arrays to organize the parameters affecting the process and the levels at which they should vary. Instead of having to test all possible combinations like the factorial design, the Taguchi method tests pairs of combinations.

For this project, 7 control factors and 2 noise factors were chosen, as shown in figure 25 . No control factor was assigned to column $\mathrm{H}$. From these 7 control factors, 6 control factors with 3 levels variation and 1 control factor with 2 levels variation completed the matrix. Each noise factor had 2 levels of variation.

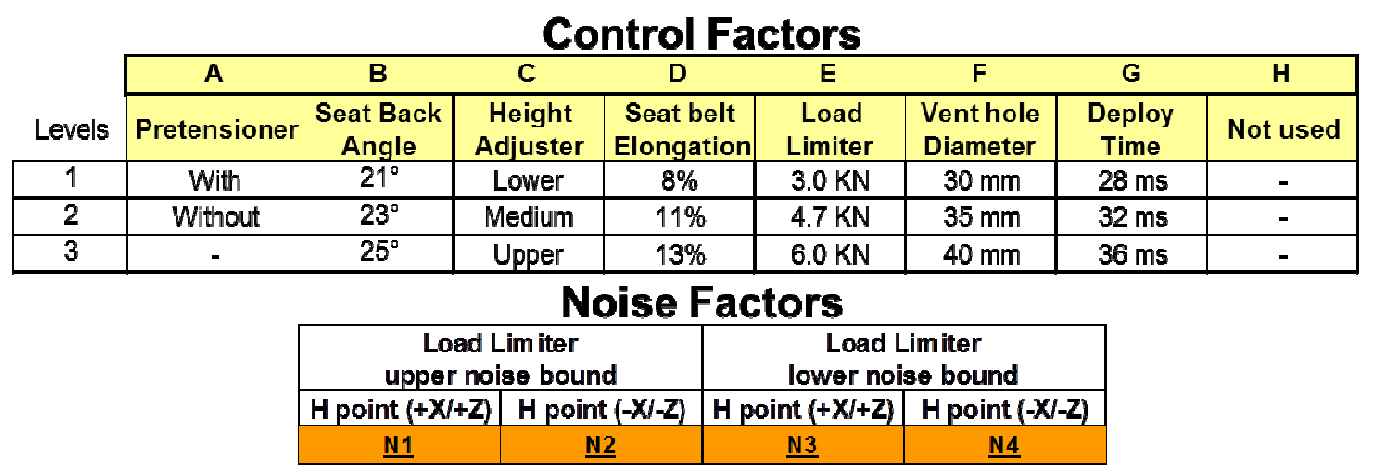

Figure 25. Control and Noise Factors evaluated

This project adopted the L18 orthogonal array that allows up to 7 control factors with 3 levels variation and 1 control factor with 2 levels variation. The L18 orthogonal array is shown in table 2 . 
Table 2. L18 orthogonal array

\begin{tabular}{|c|c|c|c|c|c|c|c|c|}
\hline & A & B & C & D & E & F & G & H \\
\hline 1 & With & $21^{\circ}$ & Lower & $8 \%$ & $3.0 \mathrm{kN}$ & $30 \mathrm{~mm}$ & $28 \mathrm{~ms}$ & - \\
2 & With & $21^{\circ}$ & Medium & $11 \%$ & $4.7 \mathrm{kN}$ & $35 \mathrm{~mm}$ & $32 \mathrm{~ms}$ & - \\
3 & With & $21^{\circ}$ & Upper & $13 \%$ & $6.0 \mathrm{kN}$ & $40 \mathrm{~mm}$ & $36 \mathrm{~ms}$ & - \\
\hline 4 & With & $23^{\circ}$ & Lower & $8 \%$ & $4.7 \mathrm{kN}$ & $35 \mathrm{~mm}$ & $36 \mathrm{~ms}$ & - \\
5 & With & $23^{\circ}$ & Medium & $11 \%$ & $6.0 \mathrm{kN}$ & $40 \mathrm{~mm}$ & $28 \mathrm{~ms}$ & - \\
6 & With & $23^{\circ}$ & Upper & $13 \%$ & $3.0 \mathrm{kN}$ & $30 \mathrm{~mm}$ & $32 \mathrm{~ms}$ & - \\
\hline 7 & With & $25^{\circ}$ & Lower & $11 \%$ & $3.0 \mathrm{kN}$ & $40 \mathrm{~mm}$ & $32 \mathrm{~ms}$ & - \\
8 & With & $25^{\circ}$ & Medium & $13 \%$ & $4.7 \mathrm{kN}$ & $30 \mathrm{~mm}$ & $36 \mathrm{~ms}$ & - \\
9 & With & $25^{\circ}$ & Upper & $8 \%$ & $6.0 \mathrm{kN}$ & $35 \mathrm{~mm}$ & $28 \mathrm{~ms}$ & - \\
\hline 10 & Without & $21^{\circ}$ & Lower & $13 \%$ & $6.0 \mathrm{kN}$ & $35 \mathrm{~mm}$ & $32 \mathrm{~ms}$ & - \\
11 & Without & $21^{\circ}$ & Medium & $8 \%$ & $3.0 \mathrm{kN}$ & $40 \mathrm{~mm}$ & $36 \mathrm{~ms}$ & - \\
12 & Without & $21^{\circ}$ & Upper & $11 \%$ & $4.7 \mathrm{kN}$ & $30 \mathrm{~mm}$ & $28 \mathrm{~ms}$ & - \\
\hline 13 & Without & $23^{\circ}$ & Lower & $11 \%$ & $6.0 \mathrm{kN}$ & $30 \mathrm{~mm}$ & $36 \mathrm{~ms}$ & - \\
14 & Without & $23^{\circ}$ & Medium & $13 \%$ & $3.0 \mathrm{kN}$ & $35 \mathrm{~mm}$ & $28 \mathrm{~ms}$ & - \\
15 & Without & $23^{\circ}$ & Upper & $8 \%$ & $4.7 \mathrm{kN}$ & $40 \mathrm{~mm}$ & $32 \mathrm{~ms}$ & - \\
\cline { 2 - 8 } 16 & Without & $25^{\circ}$ & Lower & $13 \%$ & $4.7 \mathrm{kN}$ & $40 \mathrm{~mm}$ & $28 \mathrm{~ms}$ & - \\
17 & Without & $25^{\circ}$ & Medium & $8 \%$ & $6.0 \mathrm{kN}$ & $30 \mathrm{~mm}$ & $32 \mathrm{~ms}$ & - \\
18 & Without & $25^{\circ}$ & Upper & $11 \%$ & $3.0 \mathrm{kN}$ & $35 \mathrm{~mm}$ & $36 \mathrm{~ms}$ & - \\
\hline
\end{tabular}

L18 orthogonal array was combined with the noise factors applicable for this project. This combination generated a Design Of Experiments (DOE) matrix that provided data to run 72 simulations (CAE assessment) as shown on table 3.

Table 3. DOE matrix

\begin{tabular}{|c|c|c|c|c|c|c|c|c|c|c|c|}
\hline & & & Pretensioner & $\begin{array}{c}\text { Seat Back } \\
\text { Aligly }\end{array}$ & $\begin{array}{c}\text { Height } \\
\text { Adjustor }\end{array}$ & $\begin{array}{l}\text { Seat belt } \\
\text { Elvingationn }\end{array}$ & $\begin{array}{c}\text { Load } \\
\text { Limititer } \\
\text { (NOMINAL) }\end{array}$ & $\begin{array}{l}\text { Vent hole } \\
\text { Diantilter }\end{array}$ & $\begin{array}{l}\text { Deploy } \\
\text { Tirity }\end{array}$ & $\begin{array}{l}\text { Load } \\
\text { Limiter } \\
\text { (Nuist } \\
\text { Factor) }\end{array}$ & $\begin{array}{l}\text { H Point } \\
\text { (Noise } \\
\text { Factor) }\end{array}$ \\
\hline 1 & N1 & Armulation 1 & Wh & $21^{\circ}$ & Lower & 6\% & $3.0 \mathrm{~N}$ & $30 \mathrm{~mm}$ & $28 \mathrm{~ms}$ & $3.5 \mathrm{WN}$ & $+X+Z$ \\
\hline 1 & N2 & Simmetion 2 & Min & $21^{\circ}$ & Lower & B\% & $3.0 \mathrm{~N}$ & $30 \mathrm{~mm}$ & $28 \mathrm{~ms}$ & 3.5W & $-X-Z$ \\
\hline 1 & ㄱ3 & Imultion 3 & Win & $21^{\circ}$ & Lowar & B\% & $3.0 \mathrm{NN}$ & $30 \mathrm{~mm}$ & $28 \mathrm{~ms}$ & 25wN & $+\mathbf{X}+\mathbf{Z}$ \\
\hline 1 & N4 & smation 4 & Win & $21^{\circ}$ & Lower & $8 \%$ & $3.0 \mathrm{~N}$ & $30 \mathrm{~mm}$ & $28 \mathrm{~ms}$ & 25 WN & $-\mathbf{X}-\mathbf{Z}$ \\
\hline 2 & N1 & malition 5 & Whith & $21^{\circ}$ & Medum & $11 \%$ & $4.7 \mathrm{~N}$ & $35 \mathrm{~mm}$ & $32 \mathrm{~ms}$ & $52 \mathrm{~N}$ & $+\mathbf{X}+\mathbf{Z}$ \\
\hline 2 & N2 & S-multion 6 & Whith & $21^{\circ}$ & Medum & $11 \%$ & $4.7 \mathrm{~N}$ & $35 \mathrm{~mm}$ & $32 \mathrm{~ms}$ & $52 \mathrm{~N}$ & $-\mathbf{X U}-\mathbf{Z}$ \\
\hline 2 & N33 & Enmuliten 7 & Whith & $21^{\circ}$ & Medium & $11 \%$ & $4.7 \mathrm{~N}$ & $35 \mathrm{~mm}$ & $32 \mathrm{~ms}$ & $42 \mathrm{~N}$ & $+\mathbf{X} \mathbf{I + Z}$ \\
\hline 2 & 俞4 & Amilution 8 & Wh & $21^{\circ}$ & Medium & $11 \%$ & $4.7 \mathrm{~N}$ & $35 \mathrm{~mm}$ & $32 \mathrm{~ms}$ & $42 \mathrm{~N}$ & $-x<-Z$ \\
\hline 3 & N1 & Antuten $\mathrm{g}$ & Whith & $21^{\circ}$ & Upper & $13 \%$ & 6.0NN & $40 \mathrm{~mm}$ & $36 \mathrm{~ms}$ & $6.5 \mathrm{~N}$ & $+\mathbf{X} \mathbf{+ Z}$ \\
\hline 3 & N2 & shentition wo & wh & $21^{\circ}$ & Upper & $13 \%$ & 6.0N & $40 \mathrm{~mm}$ & $36 \mathrm{~ms}$ & $6.5 \mathrm{w}$ & $-x-z$ \\
\hline 3 & N3 & atriten 11 & Wh & $21^{\circ}$ & Upper & $13 \%$ & $6.0 \mathrm{NN}$ & $40 \mathrm{~mm}$ & $36 \mathrm{~ms}$ & $5.5 \mathrm{w}$ & $+X+Z$ \\
\hline 3 & N4 & Sheltion of & Wih & $21^{\circ}$ & Upper & $13 \%$ & $6.0 \mathrm{~N}$ & $40 \mathrm{~mm}$ & $36 \mathrm{~ms}$ & $5.5 \mathrm{kN}$ & $-X-Z$ \\
\hline 4 & N1 & Sheltion 9 & Win & $2 \mathbf{3}^{\circ}$ & Lower & B\% & $4.7 \mathrm{NN}$ & $35 \mathrm{~mm}$ & $36 \mathrm{~ms}$ & 5.2W & $+\mathbf{X}+\mathbf{Z}$ \\
\hline 4 & N2 & anction 14 & Win & $\mathbf{2 3}$ & Lower & B\% & $4.7 \mathrm{~N}$ & $\mathbf{3 5} \mathbf{~ m m}$ & $36 \mathrm{~ms}$ & $52 \mathrm{~N}$ & $-x \mid-z$ \\
\hline 4 & $\underline{\mathrm{N} 3}$ & Shenten 15 & Whith & $23^{\circ}$ & Lower & B\% & $4.7 \mathbf{N}$ & $35 \mathrm{~mm}$ & $36 \mathrm{~ms}$ & 42W N & $+\mathbf{X}+\mathbf{Z}$ \\
\hline 4 & $\mathrm{N4}$ & sinction 16 & Whith & $\mathbf{2 3}$ & Lower & $8 \%$ & $4.7 N$ & $35 \mathrm{~mm}$ & $36 \mathrm{~ms}$ & 4.2W & $-\mathbf{X}-\mathbf{Z}$ \\
\hline 5 & N1 & - $=$ & Whin & $\mathbf{2 3}^{\circ}$ & Medium & $11 \%$ & 6.0N & $40 \mathrm{~mm}$ & $28 \mathrm{~ms}$ & $6.5 \mathrm{wN}$ & $+\mathbf{X} 1+\mathbf{Z}$ \\
\hline 5 & N2 & atson 18 & Win & $23^{\circ}$ & Medium & $11 \%$ & $6.0 \mathrm{~N}$ & $40 \mathrm{~mm}$ & $28 \mathrm{~ms}$ & $6.5 \mathrm{~N}$ & $-\mathbf{x} \mathbf{- Z} \mathbf{Z}$ \\
\hline 5 & 스 & achention to & Win & $23^{a}$ & Mediun & $11 \%$ & 6.0NN & $40 \mathrm{~mm}$ & $28 \mathrm{~ms}$ & $5.5 \mathrm{wN}$ & $+\mathbf{X}+\mathbf{Z}$ \\
\hline 5 & N4 & ancution ze & Win & $23^{\circ}$ & Medum & $11 \%$ & 6.0NN & $40 \mathrm{~mm}$ & $28 \mathrm{~ms}$ & $5.5 \mathrm{WN}$ & $-X^{\prime} \mid-Z$ \\
\hline 6 & $\underline{\mathrm{N} 1}$ & $\sin 4 \operatorname{lin} 21$ & Wih & $23^{\circ}$ & Upper & $13 \%$ & $3.0 \mathrm{NN}$ & $30 \mathrm{~mm}$ & $32 \mathrm{~ms}$ & 3.5W N & $+\mathbf{X}+\mathbf{Z}$ \\
\hline 6 & N2 & Simbion 22 & $\min$ & $23^{a}$ & Upper & $13 \%$ & $3.01 \mathrm{~N}$ & $30 \mathrm{~mm}$ & $32 \mathrm{~ms}$ & 3.5WN & $-\mathbf{X}_{-Z}$ \\
\hline 6 & $\underline{\mathrm{N} 3}$ & 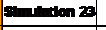 & Win & $23^{\circ}$ & Upper & $13 \%$ & 3.01N & $30 \mathrm{~mm}$ & $32 \mathrm{~ms}$ & 25wN & $+\mathbf{X}+\mathbf{Z}$ \\
\hline 6 & N4 & whention 24 & Whin & $\mathbf{2 3}^{\mathbf{n}}$ & Upper & $13 \%$ & $3.0 \mathrm{~N}$ & $3 \mathrm{~mm}$ & $32 \mathrm{~ms}$ & 26 w & $-\mathbf{x}-\mathbf{z}$ \\
\hline 7 & N1 & $\sin 25$ & Whin & $25^{n}$ & Lower & $11 \%$ & $3.0 \mathrm{NN}$ & $40 \mathrm{~mm}$ & $32 \mathrm{~ms}$ & 3.FkN & $+\mathbf{X} \mathbf{+ Z}$ \\
\hline 1 & $\mathrm{~N} 2$ & Shltion 2 & Win & $25^{\circ}$ & Lower & $11 \%$ & 3.0N & $40 \mathrm{~mm}$ & $32 \mathrm{~ms}$ & $3.5 \mathrm{WN}$ & $-\mathbf{X}-\mathbf{Z}$ \\
\hline $\begin{array}{l}7 \\
7\end{array}$ & $\begin{array}{l}\text { N3 } \\
\text { N4 }\end{array}$ & 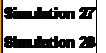 & $\begin{array}{l}\text { With } \\
\text { With }\end{array}$ & $\begin{array}{l}25^{\circ} \\
25^{\circ}\end{array}$ & $\begin{array}{l}\text { Lower } \\
\text { Lower }\end{array}$ & $\begin{array}{l}11 \% \\
11 \%\end{array}$ & $\begin{array}{l}3.0 \mathrm{~N} \\
3.0 \mathrm{~N}\end{array}$ & $\begin{array}{l}40 \mathrm{~mm} \\
40 \mathrm{~mm}\end{array}$ & $\begin{array}{l}32 \mathrm{~ms} \\
32 \mathrm{mss}\end{array}$ & $\begin{array}{l}25 \text { N } \\
25 W N\end{array}$ & $\begin{array}{l}+\mathbf{X} / \mathbf{+ Z} \\
-\mathbf{X} \mid \mathbf{Z}\end{array}$ \\
\hline 8 & N1 & 2hention 2 & With & $25^{\circ}$ & Medum & $13 \%$ & $4.7 \mathbf{N}$ & $30 \mathrm{~mm}$ & $36 \mathrm{~ms}$ & $52 \mathrm{~N}$ & $+\mathbf{X}+\mathbf{Z}$ \\
\hline 8 & N2 & anciluten as & With & $25^{\circ}$ & Medum & $13 \%$ & $4.7 \mathrm{~N}$ & $30 \mathrm{~mm}$ & $36 \mathrm{~ms}$ & 52.N & $-\mathbf{X} \mathbf{H} \mathbf{Z}$ \\
\hline 8 & $\underline{\mathrm{N} 3}$ & anturan & Win & $25^{\circ}$ & Medum & $13 \%$ & $4.7 \mathrm{~N}$ & $30 \mathrm{~mm}$ & $36 \mathrm{~ms}$ & 42WN & $+X+Z$ \\
\hline 8 & $\underline{N 4}$ & S=1ution 32 & With & $25^{a}$ & Medium & $13 \%$ & $4.7 \mathrm{NN}$ & $30 \mathrm{~mm}$ & $36 \mathrm{~ms}$ & 4.2W & $-X \| Z$ \\
\hline 9 & N1 & Eintuion 33 & Wh & $25^{\circ}$ & Upper & $6 \%$ & $6.0 \mathrm{~N}$ & $35 \mathrm{~mm}$ & $28 \mathrm{~ms}$ & $6.5 \mathrm{w}$ & $+\mathrm{X}+\mathbf{Z}$ \\
\hline 9 & $\underline{\mathrm{N} 2}$ & sharition 34 & Wilh & $25^{\circ}$ & Upper & B\% & $6.0 \mathrm{NN}$ & $35 \mathrm{~mm}$ & $28 \mathrm{~ms}$ & $6.5 \mathrm{~N}$ & $-\mathbf{X}-\mathbf{Z}$ \\
\hline 9 & N33 & sinertion $x$ & Whith & $25^{P}$ & Upper & $8 \%$ & $6.01 \mathrm{~N}$ & $35 \mathrm{~mm}$ & $28 \mathrm{~ms}$ & $5.5 \mathrm{WN}$ & $+\mathbf{X} \mathbf{I}+\mathbf{Z}$ \\
\hline 9 & $\mathrm{N4}$ & $x=1$ tion 33 & With & $25^{\circ}$ & Upper & B\% & 6.01N & $35 \mathrm{~mm}$ & $28 \mathrm{~ms}$ & $5.5 \mathrm{kN}$ & $-\mathbf{X O - Z}$ \\
\hline \begin{tabular}{c|}
10 \\
10
\end{tabular} & & 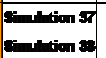 & $\begin{array}{l}\text { Without } \\
\text { Wthout }\end{array}$ & $\begin{array}{l}21^{\circ} \\
21^{\circ}\end{array}$ & $\begin{array}{l}\text { Lower } \\
\text { Lower }\end{array}$ & $\begin{array}{l}13 \% \\
13 \%\end{array}$ & $\begin{array}{l}6.0 \mathrm{~N} \\
\text { 6.OWN }\end{array}$ & $\begin{array}{l}35 \mathrm{~mm} \\
35 \mathrm{~mm}\end{array}$ & $\begin{array}{l}32 \mathrm{~ms} \\
32 \mathrm{~ms}\end{array}$ & $\begin{array}{l}\text { 6.5WN } \\
\text { 6.5WN }\end{array}$ & $\begin{array}{l}+\mathrm{X} U+\mathbf{Z} \\
-\mathrm{X} U-\mathrm{Z}\end{array}$ \\
\hline 10 & $\underline{\mathrm{N3}}$ & xiltion $=$ & Wthout & $21^{\circ}$ & Lower & $13 \%$ & 6.0NN & $35 \mathrm{~mm}$ & $32 \mathrm{~ms}$ & $5.5 \mathrm{WN}$ & $+\mathbf{X}+\mathbf{Z}$ \\
\hline
\end{tabular}




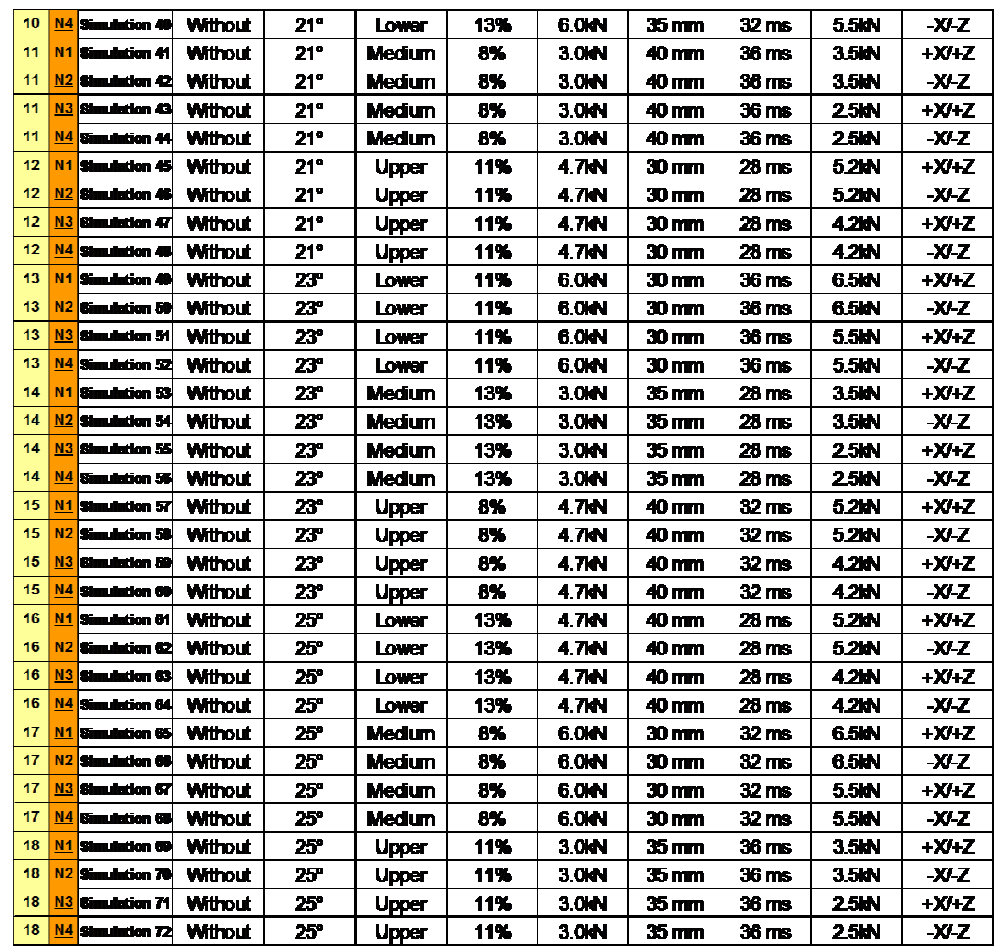

The numerical computational simulations were performed using the MADYMO software. MADYMO is a computer program that simulates the dynamic behavior of physical systems emphasizing the analysis of vehicle collisions and assessing injuries sustained by passengers. Even though the main focus is developing a passenger restraint system with the lowest chest compression, it is necessary to verify other biomechanical results (head, neck, femur, tibia and knee), in accordance to ABNT NBR 15300 option 3 (Brazil Legal Requirement).

Table 4 contains a summary (MIN, MAX and AVG) of all tested injury parameters for 72 runs. The cells filled in red in the table indicate that the legal requirement was not fulfilled; the cells filled in yellow in the table indicate that the legal requirement was fulfilled but are not lower than a pre-determined margin and the cells filled in green in the table indicate that the legal requirement and pre-determined margin were fulfilled.

Table 4. Summary results

\begin{tabular}{|c|c|c|c|c|c|c|}
\hline $\begin{array}{l}\text { Dummy } \\
\text { Region }\end{array}$ & $\begin{array}{l}\text { Injury } \\
\text { Criteria }\end{array}$ & Units & Values & $\begin{array}{l}\text { MuN } \\
\text { Value }\end{array}$ & $\begin{array}{l}\text { MAX } \\
\text { Value }\end{array}$ & $\begin{array}{l}\text { AVG } \\
\text { Value }\end{array}$ \\
\hline \multirow{2}{*}{ Head } & $\mathrm{HIC}(36 \mathrm{~ms})$ & {$[-]$} & 1000 & OK & OK & оК \\
\hline & Resultant Accelesation & [8] & 80 & $\mathrm{OK}$ & $\mathrm{OK}$ & OK \\
\hline \multirow{7}{*}{ Neck } & & \multirow{6}{*}{ [N] } & 3300 (0ms) & $\mathrm{OK}$ & OK & OK \\
\hline & $\begin{array}{c}\text { Axial Tension }(+F x) \\
\text { Duration }\end{array}$ & & $2900(35 \mathrm{~ms})$ & OK & OK & OK \\
\hline & & & $1100(60 \mathrm{~ms})$ & OK & OK & OK \\
\hline & \multirow{3}{*}{$\begin{array}{l}\text { Shear Load }(+F x) \\
\text { Duration }\end{array}$} & & $3100(0 \mathrm{~ms})$ & OK & OK & OK \\
\hline & & & 1500 (25-35ms) & OK & OK & OK \\
\hline & & & $1100\left(e^{45 \mathrm{~ms}}\right)$ & OK & OK & $\mathrm{OK}$ \\
\hline & Rearward Moment & [Nm] & 57 & $\mathrm{OK}$ & OK & $\mathrm{OK}$ \\
\hline
\end{tabular}

\begin{tabular}{|c|c|c|c|c|c|c|}
\hline $\begin{array}{l}\text { Dummy } \\
\text { Region }\end{array}$ & $\begin{array}{l}\text { Injury } \\
\text { Criteria }\end{array}$ & Units & Values & $\begin{array}{l}\text { Min } \\
\text { Value }\end{array}$ & $\begin{array}{l}\text { MAX } \\
\text { Value }\end{array}$ & $\begin{array}{l}\text { AVG } \\
\text { Value }\end{array}$ \\
\hline \multirow{2}{*}{ Thorax } & Compression (belted) & {$[\mathrm{mm}]$} & 50 & OK & OK & OK \\
\hline & Viscous Crtterlon & {$[\mathrm{m} / \mathrm{s}]$} & 1.0 & OK & OK & OK \\
\hline \multirow{2}{*}{ Ferror } & \multirow{2}{*}{$\begin{array}{l}\text { Compressive Loed - } \\
\text { Duration }\end{array}$} & \multirow{2}{*}{ [N] } & 9070 (0ms) & $\mathrm{OK}$ & OK & OK \\
\hline & & & 7980 (10ms) & $\mathrm{OK}$ & OK & $\mathrm{OK}$ \\
\hline \multirow{2}{*}{ Tibla } & Axial Compressire Load & [N] & 8000 & $\mathrm{OK}$ & NOK & OK \\
\hline & Index $=\mathrm{M} / \mathrm{Mc}+\mid \mathrm{P} / \mathbf{P e}$ & {$[-]$} & 1.3 & $\mathrm{OK}$ & OK & OK \\
\hline Knee & Sldthe (Tibla-Femur) & [mm] & 15 & OK & NOK & OK \\
\hline
\end{tabular}

Reduction of chest compression injury level is the DFSS target, but it is also necessary to analyze tibia injury levels (tibia to femur translation and tibia axial compression) that may not 
meet the legal requirement, and confirm the correlation. Simulations 44 and 71 are the only ones that do not meet the legal requirements for tibia injuries. A total of 28 simulations do not meet the pre-determined requirements for margin (23 simulations for tibia injuries and 5 simulations for chest compression). To determine which among the levels of the factor is most desirable for achieving the project objectives, it is necessary to establish the Quality Characteristic (QC) applicable. NTB (Nominal the Best) method to the optimization of the passenger restraint system was used. The graphics from figure 26 to figure 31 are based on the Signal to Noise Ratio (S/N ratio) which represents the robustness of each parameter and mean, which shows the efficiency.

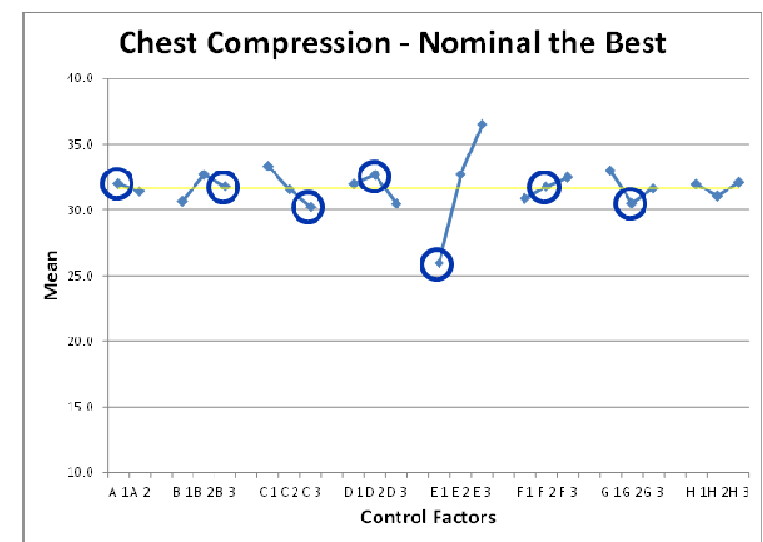

Fig.26. Chest compression to NTB (Mean)

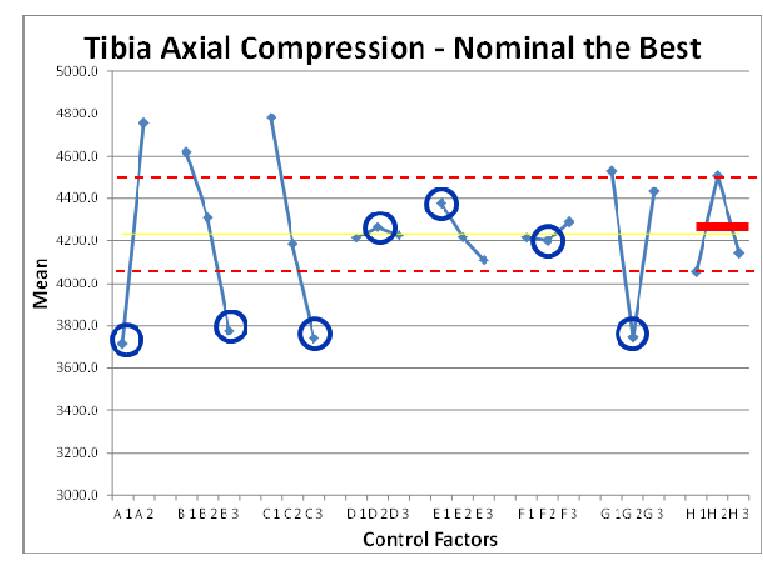

Fig.28. Tibia Axial Compression to NTB (Mean)

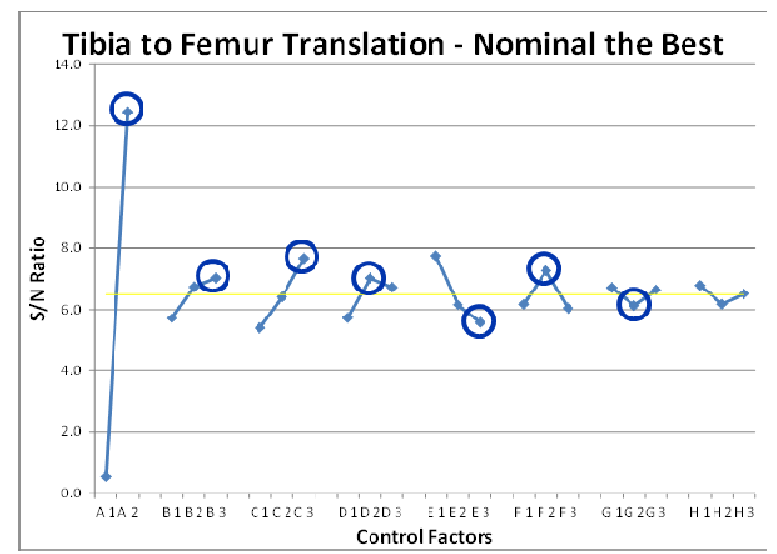

Fig.30. Tibia/Femur Translation to NTB (S/N)

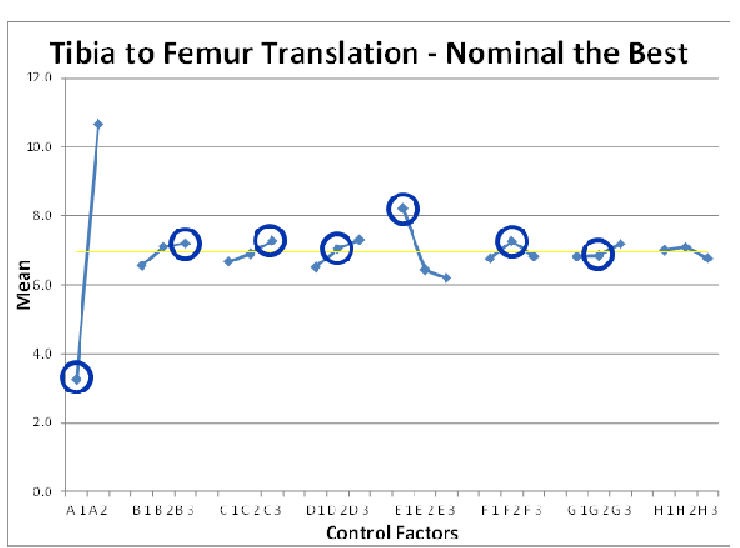

Fig.27. Tibia/Femur Translation to NTB (Mean)

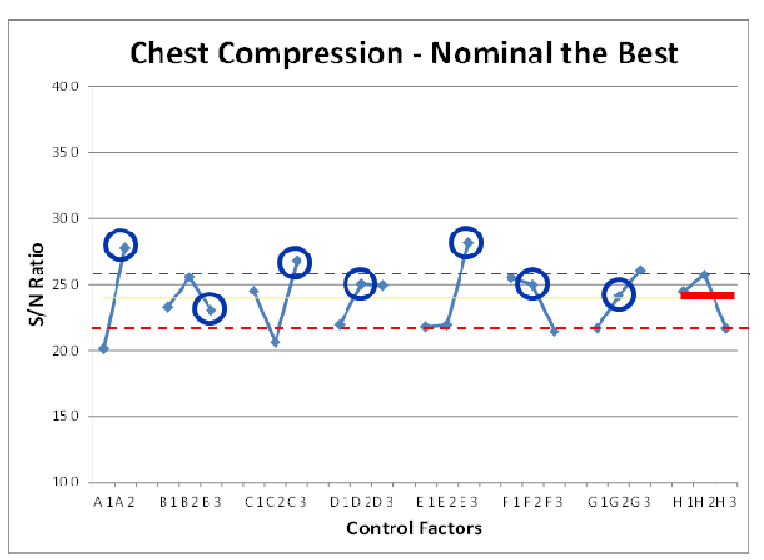

Fig.29. Chest compression to NTB (S/N)

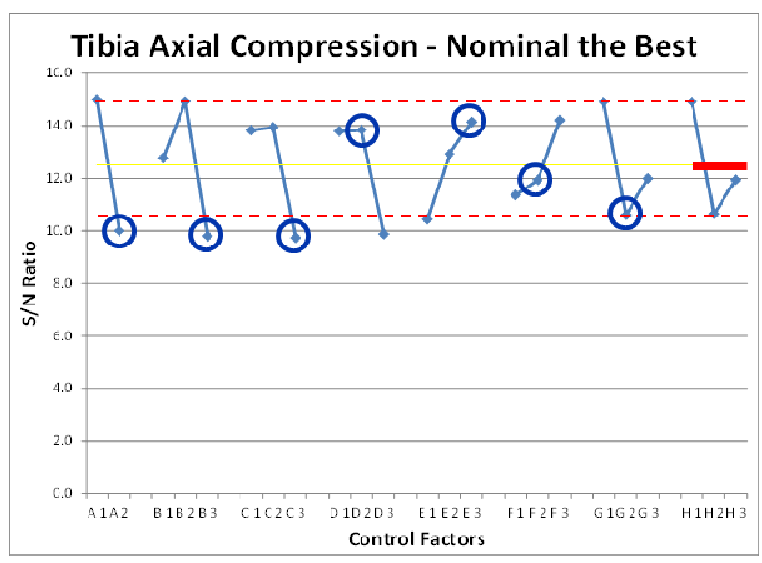

Fig.31. Tibia Axial Compression to NTB (S/N) 


\section{Analyze Data}

The optimum configuration was based on the rational described below:

- A2 is the most robust $(\mathrm{S} / \mathrm{N})$ for chest compression and tibia to femur translation, while its variation on chest compression value (average) is very small;

- B3 is the most robust ( $\mathrm{S} / \mathrm{N})$ for tibia to femur translation and present the best value (average) for tibia axial compression;

- C3 is the most robust ( $\mathrm{S} / \mathrm{N})$ for chest compression and tibia to femur translation and has the best value (average) for chest compression and tibia axial compression;

- D2 is the most robust ( $\mathrm{S} / \mathrm{N})$ for tibia to femur translation and presents similar values (average) for all outputs and has the lowest impact on current project (no changes are necessary);

- E3 is the most robust $(\mathrm{S} / \mathrm{N})$ for chest compression, so this selection will give the most robust target result with lower cost control factor;

- F2 is the most robust ( $/ \mathrm{N}$ ) for tibia to femur translation and presents intermediate values (average) for all outputs and has the lowest impact on current project (no changes are necessary);

- G2 was chosen because it presents the best values (average) for chest compression and tibia axial compression, while its variation on tibia to femur translation value is very small;

- No variable was assigned to column $\mathrm{H}$. The response to $\mathrm{H}$ ought to be flat (as shown in solid red line at tibia axial compression graphic) if there are no errors or interactions. Since this is CAE, it is likely an interaction. Control factors with response less than $\mathrm{H}$ (dashed red line) are not reliable.

\section{$\underline{\text { Predict and Confirm }}$}

Based on the graphics analyses and the rational presented previously the optimum configuration was defined as follows:

Table 5. Optimum configuration

\begin{tabular}{|c|c|c|}
\hline \multicolumn{3}{|c|}{ Optimum } \\
\hline Level & Description & Definition \\
\hline A2 & Pretensioner & Without \\
\hline B3 & Seat Back Angle & $25^{\circ}$ \\
\hline C3 & Height Adjuster & Upper \\
\hline D2 & Seat Belt Elongation & $11 \%$ \\
\hline E3 & Load Limiter & $6.0 \mathrm{kN}$ \\
\hline F2 & Vent Hole Diameter & $35 \mathrm{~mm}$ \\
\hline G2 & Deploy Time & $32 \mathrm{~ms}$ \\
\hline
\end{tabular}

A prediction was made with the optimized design and the results showed better values for chest compression with a robustness gain for NTB method compared to baseline design. Furthermore, an additional computational numerical simulation was performed applying the nominal optimized parameters to have its confirmation. The CAE model showed excellent chest compression correlation comparing to the predicted value as shown in the table 6 normalized. 
Table 6. Confirmation results to nominal condition

\begin{tabular}{|c|c|}
\hline Nominal Condition & $\begin{array}{c}\text { Chest } \\
\text { Compression }\end{array}$ \\
\hline Optimized Design (Predicted) & 1,0000 \\
\hline CAE results & 1,0029 \\
\hline
\end{tabular}

Note: the values are normalized by the optimized design predicted.

If considering the noise factors tolerances to the load limiter and the h-point, (see table 7 normalized) the variation in the chest compression results can be verified.

Table 7. Confirmation with noise factors tolerance

\begin{tabular}{|l|c|c|c|}
\hline & $\begin{array}{c}\text { Load Limiter } \\
\text { (Noise Factor) }\end{array}$ & $\begin{array}{c}\text { H-point } \\
\text { (Noise Factor) }\end{array}$ & $\begin{array}{c}\text { Chest } \\
\text { Compression }\end{array}$ \\
\hline $\begin{array}{l}\text { Optimized Design } \\
\text { Nominal (Predict) }\end{array}$ & 6.0 & - & 1,0 \\
\hline CAE tolerances 1 & 5.5 & $+\mathrm{X} /+\mathrm{Z}$ & 0,9942 \\
\hline CAE tolerances 2 & 5.5 & $-\mathrm{X} /-\mathrm{Z}$ & 0,9740 \\
\hline CAE tolerances 3 & 6.5 & $+\mathrm{X} /+\mathrm{Z}$ & 1,0260 \\
\hline CAE tolerances 4 & 6.5 & $-\mathrm{X} /-\mathrm{Z}$ & 1,0144 \\
\hline
\end{tabular}

Note: the values are normalized by the optimized design predicted.

\section{Document}

The predicted and confirmed values presented better performance than current baseline model and met the chest compression target for this project with a better $\mathrm{S} / \mathrm{N}$ compared with the baseline.

\section{IDOE - Validate}

The goal of this phase was demonstrate the project achieved its goals and objectives. The Vehicle Safety Team performed a frontal 56kph $40 \%$ ODB LHS crash test to validate the project. Crash test setup was defined according the optimum configuration. The frontal barrier test met the legal requirements and chest compression values when comparing to the predicted and confirmed values as shown in the table 8 normalized.

Table 8. Crash test validation

\begin{tabular}{|c|c|}
\hline $\begin{array}{c}\text { Nominal Condition } \\
\text { Optimized Design } \\
\text { (Predicted) }\end{array}$ & $\begin{array}{c}\text { Chest } \\
\text { Compression }\end{array}$ \\
\hline CAE results & 1,0000 \\
\hline Crash test & 0,9653 \\
\hline
\end{tabular}




\section{CONCLUSION}

The predicted and confirmed values presented better performance than current baseline model and met the chest compression target for this project with a better S/N compared with the baseline. Based on these results, a physical crash test was conducted considering the control factors shown with the optimum configuration to support the verification phase. This experimental test confirmed the performance. The stated goals for this project were therefore achieved. Based on the DFSS and CAE results that bring us a good confidence level, a crash test was conducted without a prior sled test to confirm this optimum configuration. As noted, the focus of the project was chest compression, which correlated well for this model. The final crash test confirmed the project met the CONTRAN requirements with adequate margin in the verification phase.

\section{ACKNOWLEDGMENTS}

The authors wish to acknowledge the engineers and technicians at General Motors Cruz Alta Proving Ground, Brazil, for their help in developing and conducting these analyses and tests. Also, our acknowledgments to Vehicle Synthesis, Analysis \& Simulation (VSAS) team for numerical computational simulations and analyses.

\section{RECOMMENDED FUTURE WORK}

Future DFSS studies to combine simultaneously driver and passenger optimizations in order to produce a shared cost effective restraint system design.

\section{REFERENCES}

[1] Miller, Ryan A.; and Allen, Brian T. Injury optimization of the frontal crash supplemental restraint system (SRS) deployment matrix, $20^{\text {th }}$ International Technical Conference on the Enhanced Safety of Vehicles, Paper No. 2007-0073.

[2] Roy, Ranjit K. Design of Experiments using Taguchi Approach.

[3] MADYMO Theory Manual. Release 6.4.1 December 2007. 